\title{
Streamlining Supply Chain Management With E-Business
}

\author{
Mehmet C. Kocakulah, (E-Mail: Mkocakul@usi.edu), University of Southern Indiana \\ Abbas Foroughi, (Email: aforough@usi.edu), University of Southern Indiana \\ Mitchell Lannert, Arthur Andersen LLP, Indianapolis, IN
}

\begin{abstract}
In today's highly technologically driven business environment, companies must be on the leading edge of technology in order to remain competitive. If properly implemented and managed, technology can lead to considerable benefits throughout the organizations business functions. One major benefit of e-business is the ability to more efficiently manage the supply chain. The process of developing and implementing e-business can consume a large amount of resources and may pose some managerial challenges. However, the benefits derived from e-business will more than justify the costs expended and will allow a business to remain competitive and sustain a competitive advantage.
\end{abstract}

\section{Introduction}

भु he Internet has revolutionized many aspects of business. Companies that are still using old business practices such as linear, sequential supply chains are finding themselves no longer able to keep up with the competition. Meanwhile, those who have begun using e-business are experiencing the benefits which the speed, flexibility, and real-time communication of the Internet give to supply chain management. Ebusiness increases levels of communication and collaboration both internally and externally by streamlining the flow of information within the company and between the company and external business partners. This flow of information can be used to benefit the companies' core business processes. According to Lou Gerstner, Jr., IBM chairman and CEO, e-business can benefit front-end relationships with customers and investors, back-end relationships across the supply chain, and internal transactions such as order processing and employee processes (Informationweek.com, 2000).

This paper describes the impact of e-business on supply chain management, discusses managerial challenges of implementing e-business systems in supply chain management, and presents examples of businesses who have gained a competitive edge through the implementation of online supply chain management.

\section{The Supply Chain}

The supply chain according to Laudon and Laudon is a collection of physical entities linked together into processes that supply goods or services from source through consumption (2000). The physical entities in the supply chain consist of suppliers, manufacturers, distributors, retail outlets, and consumers. The following diagram demonstrates the flow of goods through the supply chain starting with the supplier and ending with the consumer.

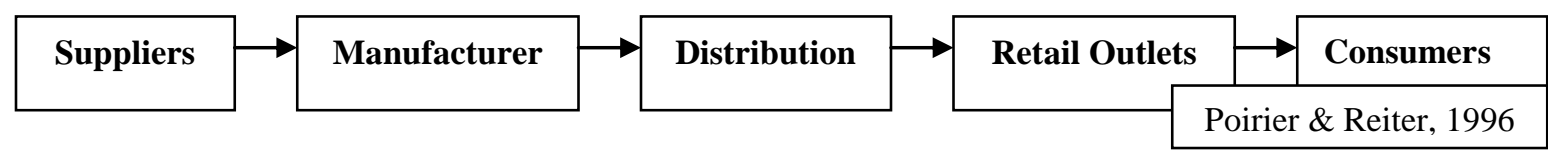

Readers with comments or questions are encouraged to contact the authors via email. 
The beginning of the supply chain starts with the suppliers, which are the entities that provide such items as raw materials, ingredients, and commodities. These raw materials and other supplies are then transferred to the manufacturer. The manufacturer uses these materials to build, assemble, or convert the materials into a finished product or service. The finished products are then transferred to a distribution center. The distributor warehouses the goods or delivers them to retail outlets. The retail outlets, such as grocery stores and department stores, then store the goods until the ultimate purchase by the consumer (Poirier and Reiter, 1996).

Managing the supply chain is not an easy task. Effective supply chain management requires integrating the supplier, manufacturer, distributor, retail outlets, and customer requirements into one cohesive process (Laudon and Laudon, 2000). This requires utilizing the expertise of all the entities involved in the supply chain. According to Riggs and Robbins, utilizing the expertise of all functions in the supply change will lead to effective supply chain management. Supply chain management can examine all facets of the buying and actual use of

purchased materials and services and link the resources of leading suppliers to strategic company goals, thus strengthening competitive advantage in the marketplace (1998).

\section{Facilitating Supply Chain Management With E-Business}

To efficiently manage the supply chain, all functions and entities of the supply chain must be fully integrated. This integration can be made possible through the use of communications networks, which allow collaboration among the various entities and functions of the supply chain. This communications network is the heart of ebusiness.

The following diagram depicts how e-business can efficiently distribute and coordinate the flow of information between the entities and business functions of the supply chain.

\section{How E-Business Can Integrate Information from Business Processes to Facilitate Supply Chain Management}

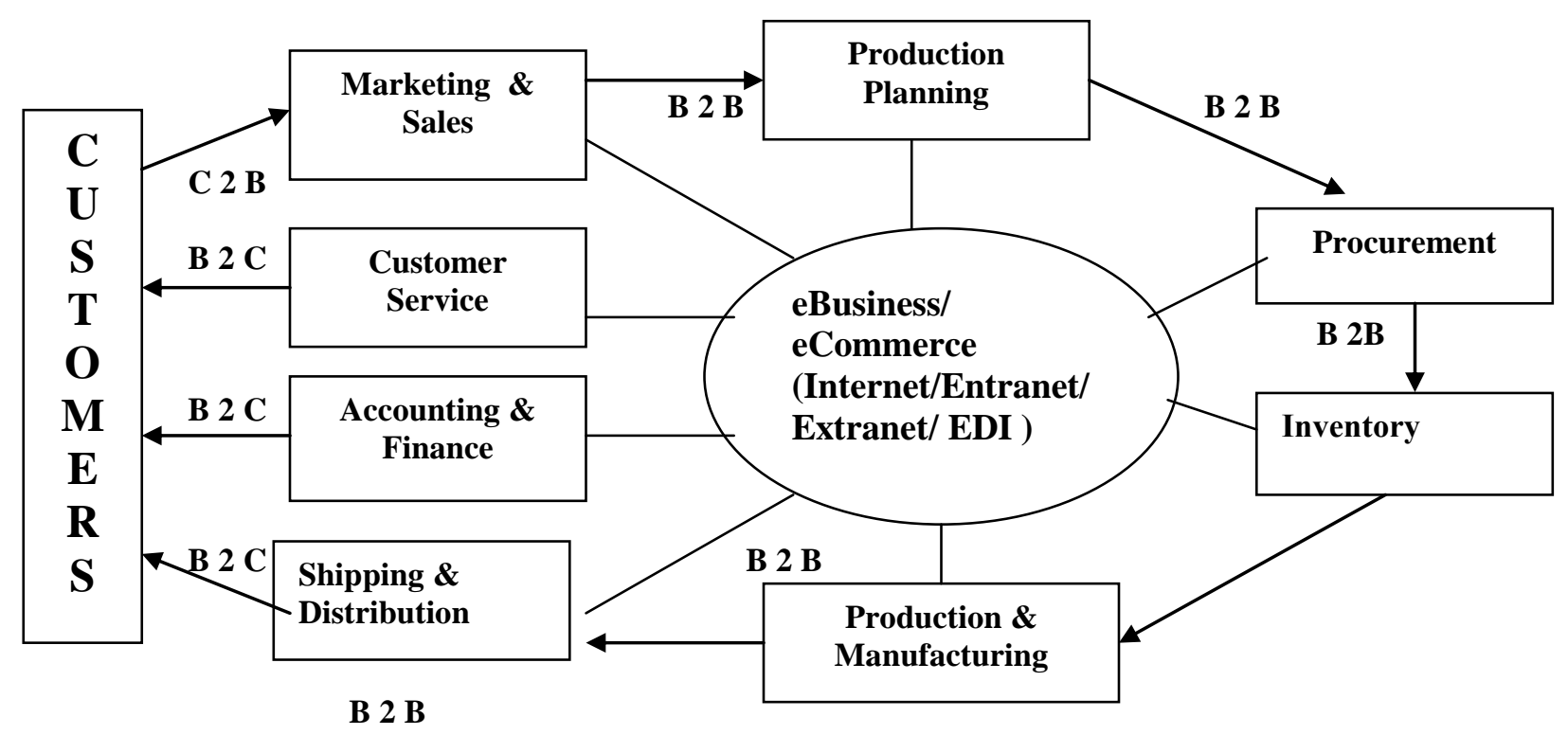

Business to Customer (B 2 C) Business to Business (B 2 B)

(Adapted from Kalakota, Ravi and Whinston, 1997, p.293) 
Many variations of communications networks and technologies can be built and used to facilitate supply chain management with e-business. Four examples include the Internet, a company intranet, an extranet, and Electronic Data Interchange (EDI).

The Internet is a collection of public and private communications network that links businesses to consumers and businesses to businesses. The speed and ease of use of the Internet can facilitate the flow of information from the retailer to the customer and vice versa, which can result in cost reductions associated with order processing and customer service.

Another valuable network in e-business is a company intranet, which is based on Internet technology, but is used primarily within a single company or organization. The intranet allows internal users to share information with each other and may span multiple locations throughout the world (Bartoo, Elliot, and Naik-lyer, 2000).

The intranet of e-business can be a very valuable tool that can lead to significant cost reductions in internal business processes because of the ease of accessing information from various functions within the organization. For example, many company intranets are used as on-line repositories of information, which can be updated as often as required. Documents such as products catalogs, employee handbooks, or benefits information can be made accessible to all users of the intranet. These documents can always be up-to-date, eliminating paper, printing, and distribution costs. Using a paper-based model of distributing information can cost an organization an estimated $\$ 15$ per employee (Laudon and Laudon, 2000). Organizations can save millions of dollars by just converting a single application, such as an employee policy and benefits manual, to electronic form on an intranet (Levitt, 1996).

Intranets can also aid in the facilitating of the supply chain from retailer to customer. Marketing and sales, accounting and finance, and customer service are all linked together through the company intranet. Each function has access to information from the other functions. Therefore, the organization can reduce costs in such areas as order processing and credit checking of customers without sacrificing customer service.

To facilitate all the other functions of the supply chain, two primary technologies of e-business are used-extranets and electronic data interchange (EDI).

Extranets are similar to intranets, but instead of solely being internal to the company, the extranet extends the company's intranet to other companies and organizations, such as suppliers, manufacturers, and distributors (Bartoo, Elliott, and Naik-lyer, 2000).

EDI is a popular technology used to transfer information over the extranet. EDI is a key technology of ebusiness because it allows the computer-to-computer exchange of standard transaction documents between two organizations over an extranet. Examples of these documents include invoices, bills of lading, and purchase orders (Laudon and Laudon, 2000). Using EDI to transfer standard documents can reduce transaction costs and can lead to better relationships with suppliers, manufacturers, and distributors.

The use of EDI over extranets is mutually beneficial to all parties. The time and cost saved through EDI can lead to rewards such as faster communications with supply partners and better control and reduction of inventories (Francis, 2000). Organizations can also integrate data from EDI with applications such as accounts payable, inventory control, and production planning in order to further reduce costs (Premkumar, Ramanmurthy, and Nilakanta, 1994).

E-business and its components-- can be of great benefit in effectively managing the supply chain by providing connectivity and collaboration among all areas of the supply chain. E-business can coordinate and connect all of the business process such as sales, marketing, finance, and accounting to eliminate internal costs. By using the components of e-business, companies can work directly with suppliers and manufacturers, allowing them to eliminate the intermediary costs of distribution. According to Mougayar, paying for all the steps in a traditional distribution channel can increase a product's price as high as 135 percent of its original cost to manufacture. Reducing the number of intermediaries can help companies achieve higher profits while charging lower prices (1998). 


\section{Managerial Challenges Of Implementing E-Business}

With all the benefits associated with implementing e-business to facilitate supply chain management, one would think companies would jump at the chance to reap the benefits of e-business. However, this is not the case. There are many managerial challenges associated with implementing e-business and its components.

Implementing e-business can entail the use of a considerable amount of capital resources. Capital outlays and resources are made to cover the initial investment, hardware and software requirements, salaries of information systems specialists, and maintenance and up-dating costs of the system. These costs can be considerable and may deter some companies from implementing e-business. Today's customers expect orders to be filled much more quickly than in the past. Many distribution centers and warehouses, used to dealing with pallet-size orders, are not set up for dealing with a lot of single-item or open-case shipping. "To configure a warehouse to do that type of picking requires a lot of physical changes in the facility," said Dan Trew, vice president of product strategy at Milwaukee's Catalyst International (Murphy, 2000, 3). Revamping and reorganizing warehouses can be costly, as is the acquirement of software systems to speed up the supply chain. However, Brynjolfsson and Hitt, after examining the information systems spending of 380 large firms during a five-year period, found that the return on investment averaged more than 50 percent each year (1993).

A second challenge managers face when implementing e-business is organizational change. New systems often require new ways of doing business and working together (Laudon and Laudon, 2000). Managing organizational change and enlisting the involvement of employees in all areas of the business can be difficult and time consuming. It requires close collaboration on the parts of all individuals at all levels of the organization. Configuration of a warehouse to accommodate single-item orders instead of just pallet-size orders, for example, makes for a much more labor-intensive workplace that requires a change in work flow patterns (Murphy, 2000). Organizational change is by far one of the greatest deterrents of implementing an e-business strategy. Lori Morgan, Director of Logistics at Kraft Food North America emphasized the importance of involving all employees, at each point in the supply chain, in changes to a company's supply chain management. She said, "the more employees understand about Kraft processes and the way the world of Kraft works today, the more opportunity we have for ideation and understanding how to change to meet those needs going forward (Kraft, 2001, 6)." If management can carefully orchestrate the divisions, production sites, sales offices, and relationships with customers, suppliers, and other trading partners, the use of e-business to facilitate supply chain management will be a success and the company and their trading partners will reap the benefits.

Ever more rapid, correct, on-time deliveries are expected by consumers and businesses. Failure to deliver well and on-time can lose business or result in significant penalties (Wybo, 2001). Industries are having to adapt their company culture to accommodate the aspect of speed in their operations. "The bottom line is that speed is everything; size no longer matters. It used to be in business that the big would eat the small. Now, it's the fast that are overtaking and eating the big, said Henry Bruce, vice president of global marketing at software vendor Optum (Murphy, 2000, 4). "Responsiveness is to the internet age what efficiency was to the industrial age."

Another challenge faced by management concerns the privacy and security of their e-business networks. Managers often ask, "How can we make sure our intranet is secure from entry by outsiders?" They also ask, "Are we doing enough to protect the privacy of customers we reach electronically?" (Laudon and Laudon, 2000). Also when establishing extranets to connect to manufacturers and suppliers, managers may ask, "Whom do we trust?" If you can't trust your business and trading partners, the system breaks down in a hurry (Blackwell, 1997). Many companies are beginning to use Collaborative Planning, Forecasting, and Replenishment (CPFR), a process that facilitates the sharing of information between trading partners to lower costs and improve the speed of inventory and information in the supply chain (Nabisco, 2001).

Developing the right supply chain application to provide the desired solutions is not an easy process, but there are several guidelines to follow. The system must be easy and inexpensive to implement, with minimum disruption to normal operations. A system with industry-specific functionality is preferable to a highly customized system. The benefits to a company's supply chain must be obvious and the return on investment quick. Companies 
seeking the expertise of a consultant firming should choose one that has a solid track record of success in other similar industries and whose solution will not require the complete overhaul of the company's infrastructure (Wybo. 2001).

\section{E-Business In Practice}

Many companies are using e-business and its related components to facilitate supply chain management. These firms are realizing a variety of benefits such as cost reduction and more responsive customer service. Furthermore, the benefits of e-business on supply chain management are being realized both domestically and globally.

\section{American Honda}

Until the mid-1990s, American Honda, like most other carmakers, lacked the capability to respond quickly to consumer demand. Based on estimates of the models, colors, and features customers would want, orders were shipped to dealers. Dealers had to offer to their customers whatever they happened to receive from the factory. Special orders took up to four months to arrive. In 1996, Dan Donawitz, a vice president at American Honda, with the help of Syncata, an e-business consultancy in El Segundo, California, created a networked supply chain, the Market Oriented Vehicle Environment, which enabled everyone from headquarters to plants to dealers to collaborate to improve production flow. All 1,300 of American Honda dealers would be able to place their orders directly with Honda headquarters and be updated on order-shipment status. Once a month, dealers use virtual private networks to view suggested orders and adjust them according to current demand, if they wish. Honda uses this up-to-the-minute market data in orders sent to its seven auto plants. MOVE software is used to determine how to distribute the production load most efficiently. Since its completion in October 2000, MOVE has resulted in a drop in lead time from 120 to $30-60,95 \%$ matches of dealers' requests for cars, and a 50\% reduction in inventories at plants and at dealerships. "...the increased efficiency of being able to distribute particular vehicles to the points where the greatest demand exists for those models provides a definite competitive edge," said Stephen Keeney, American Honda spokesman (Gage, 2001, 1).

\section{O’Reilly Auto Parts}

While expanding from 260 to more than 700 retail stores and increasing the number and type of products it sold, during the 1990s, O'Reilly Auto Parts realized that its aging inventory management system, to which changes had to be coded in manually, could not handle the newly expanded scope of the business. O'Reilly turned to Score software from NonStop Solutions, in San Francisco, which could provide the capability to forecast demand levels based on historical sales patterns, track manufacturers' delivery times, and use special discounts, current inventory levels, and planned price increases to help determine how much stock to order. O'Reilly invested somewhere between $\$ 1.5$ and $\$ 2$ million on the year-long project, which enables the company to warehouse two months' worth of inventory, instead of three. This has resulted in a savings of \$50 million/year and has enabled O'Reilly to add 474 new stores and five new warehouse distribution centers (Clifford, 2001).

\section{Vail Resorts}

Vail Resorts in Colorado operates 90 restaurants, 70 shops, and 12 hotels. Until recently, Vail placed food orders, sometimes as many as 400 per day, via fax. Three food buyers spent 45 hours a month in order placement. Confirmations took up to five hours. If a vendor ran out of what was needed, little time was left to find alternative suppliers. Vail Resort consulted Network Exchange, in Bonsall, California, an application service provide which connects third parties, thus saving them installation and maintenance expenses. An internal order-entry system would enable Vail to transmit bids to its largest suppliers and receive confirmations in minutes. Vail's major suppliers, Nobel/Sysco and Alliant Foodservice, each paid \$5,000 to integrate their systems with Networld's. By eliminating the need to rekey hundreds of purchase orders daily, the new system provided the suppliers with savings in labor costs. The system was put into place in four weeks, and Vail now is assured of supplies coming on time. Michael Kubat, Vail Resort's director of procurement, has not yet seen significant drops in procurement and labor costs, but expects to when the online system is expanded to accept competitive bids from suppliers (Clancy, 2001). 


\section{IBM}

An e-Replenishment system introduced by IBM and Industri-Matematik International will increase on-shelf product availability in stores. A combination of point-of-sale data with web technology will enable real-time management of the product replenishment process. Internet-accessed in-store inventory data will enable quick decisions to be made about replenishment needs (Murphy, 2000).

\section{Marshall Industries}

Marshall Industries is the forth-largest distributor in the world of industrial electronic components and production supplies. The company built a "virtual" distribution, which converted all the physically performed processes into a digital service via e-business.

Marshall Industries' customers and suppliers have access to the company's intranet, which allows them to obtain customized information. Suppliers can view their accounts, and they can also accept or reject price quotes or order training materials. Customers can specify what categories they are interested in and receive information only specific to their interests.

Visitors can also view more than 100,000 pages of data sheets, inventory from 150 major suppliers, up-todate pricing, and information on 170,000 part numbers. They can use a search engine to locate products on Marshall's on-line catalog. When a customer places an order, the system verifies the quantity and price and initiates a real-time credit authorization and approval. After approval, the system sends a request to the warehouse. Then the customer receives an order acknowledgement and relevant shipping information, which can be accessed via a link to the United Parcel Service's web site. The system enhances customer service and integrates the entire process of placing and receiving an order (Laudon and Laudon, 2000). Marshall Industry's use of the Internet, intranet, and extranet has allowed them to reduce costs, reduce order processing time, and enhance customer service.

\section{Adaptec Inc.}

Adaptec Inc., based in Silicon-Valley, is a manufacturer of computer chips and boards. The company is using e-business to facilitate supply chain management on a global scale because the company obtains many of its parts from East Asia.

Adaptec Inc. is using the Internet component of e-business to allow the company's suppliers access to purchase orders and factory-status updates. The use of e-business by the company has made it a more responsive organization. It has cut the manufacturing cycle from 12 weeks to eight weeks by using the Internet to collaborate with suppliers.

The company has also reduced costs using the Internet. The company claims it has saved nearly $\$ 10$ million in inventory costs in only a four-month period (Laudon and Laudon, 2001).

\section{Conclusion}

In today's highly technologically driven business environment, companies must be on the leading edge of technology in order to remain competitive. If properly implemented and managed, technology can lead to considerable benefits throughout the organizations business functions. One major benefit of e-business is the ability to more efficiently manage the supply chain. The process of developing and implementing e-business can consume a large amount of resources and may pose some managerial challenges. However, the benefits derived from e-business will more than justify the costs expended and will allow a business to remain competitive and sustain a competitive advantage. 


\section{References}

1. Bartoo, Jim, Elliot, Timo, and Naik-lyer, Varsha. Increased Competitive Advantage the Combination of Ebusiness and Business Intelligence Tools. San Jose, CA: Business Objects, 2000.

2. Blackwell, Roger D. From Mind To Market: Reinventing The Retail Supply Chain. New York: HarperCollins Publishers, 1997.

3. Brynjolfsson, Erik. "The Productivity Paradox of Information Technology." Communications of the ACM 36, no. 12 (December 1993).

4. Clancy, Heather. "Case Studies: Vail Resorts." Business 2.0, March 2001. [Online] http://www.business2.com/articles/mag/0,1640,9318,FF.html

5. Clifford, Stephanie. "Case Study: O’Reilly Auto Parts." Business 2.0, August, 2001. [Online] http://www.business2.com/articles/mag/0,1640,16660,FF.hrml

6. Francis, Philip H. Product Creation: The Heart of the Enterprise from Engineering to E-Commerce. New York: Simon \& Schuster, Inc., 2000.

7. Gage, Deborah. "Case Studies: American Honda." Business 2.0, May, 2001. [Online] http://www. business2.com/articles/mag/print/0,1643,9559,00.html

8. Kalakota, Ravi, and Whinston, Andrew B. Electronic Commerce: A Manager's Guide. Reading, MA: Addison-Wesley, 1997.

9. Kraft Foods. "Supply Chain Brain Executive Interview.” Keller International Publishing, LLC, January 2001. [Online]. http://www.supplychainbrain.com/archives/1.01.morgan.htm?advode=95

10. Laudon, Kenneth C. and Laudon, Jane P. Management Information Systems: Organization and Technology in the Networked Enterprise. New Jersey: Prentice Hall, 2000.

11. Levitt, Lee. "Intranets: Internet Technologies Deployed Behind the Firewall for Corporate Productivity." Process Software Corporation, 1996.

12. Informationweek.com. "Lou Gerstner's E-business Expo Keynote Address." (2000, December 12). [Online] <http://www.informationweek.com/816/gerstner.htm> [2001, March 31].

13. Maugayar, Walid. Opening Digital Markets, $2^{\text {nd }}$ ed. New York: McGraw-Hill, 1998.

14. Murphy, Jean V. "Internet Technology Both Forces and Enables Transformation of Supply Chains." Supply Chain Brain. Keller International Publishing LLC, March 2000. [Online] http://www. supplychainbrain.com/archives/3.00intro.htm?adcode $=80$

15. NABISCO, Inc. "Supply Chain Brain Executive Interview." Keller International Publishing, LLC, January 2001. [Online] http://www.supplychainbrain.com/archives/1.01.blasgen.htm?adcode=95

16. Poirier, Charles C. and Reiter, Stephen E. Supply Chain Optimization: Building the Strongest Total Business Network. San Francisco: Berrett-Koehler Publishers, 1996.

17. Premkumer, G., K. Ramamurthy, and Sree Nilakanta. "Implementation of Electronic Data Interchange: An Innovation Diffusion Perspective." Journal of Management Information Systems 11, no. 2 (Fall 1994).

18. Riggs, David A. and Robbins, Sharon L. The Executive's Guide to Supply Management Strategies. New York: Amacom, 1998.

19. Wybo, M. "Online Supply-chain Management Key to Growth and Profitability." Supply Chain Brain. Keller International Publishing LLC, May, 2001. [Online] http://supplychainbrain.com/archives/ 5.01.opinion $2 . \mathrm{htm}$ ? adcode $=30$ 
Notes 